\title{
Electrolyte-Gated Transistors Based on Conducting Polymer Nanowire Junction Arrays
}

Maksudul M. Alam, Jun Wang, Yaoyao Guo, Stephanie P. Lee, Hsian-Rong Tseng* Crump Institute for Molecular Imaging, Department of Molecular and Medical Pharmacology, David Geffen School of Medicine at University of California, Los Angeles, California 90095

E-mail: hrtseng@mednet.ucla.edu

\section{$\underline{\text { Supporting Information }}$}

The polymer nanowire-based transistors were characterized in different concentrations (1.0, 0.1 and $0.01 \mathrm{M}$ ) of the $\mathrm{NaCl}$ electrolyte solutions while keeping the other experimental conditions and the geometry constant. The $I_{\mathrm{sd}}-V_{\mathrm{sd}}$ curves of the polypyrrole nanowire-based transistors in both 0.1 and $0.01 \mathrm{M} \mathrm{NaCl}$ electrolyte solutions are shown in Figure S1. The observed shape and characteristic of the $I_{\mathrm{sd}}-V_{\mathrm{sd}}$ curves of the transistors are identical to that in 1.0 $\mathrm{M} \mathrm{NaCl}$ solutions. No significant changes in the maximum values of $I_{\mathrm{sd}}$ and the on/off current ratios of the transistors were observed compared to those of transistors characterized in $1.0 \mathrm{M}$ $\mathrm{NaCl}$ solutions. As a control, the maximum leakage currents obtained for the blank devices were decreased proportionally with the decreasing concentrations of the $\mathrm{NaCl}$ electrolyte solutions (Figure S2).

We have further operated the transistors with the drain-source voltage $\left(V_{\mathrm{sd}}\right)$ in the range 0.6 to $+0.6 \mathrm{~V}$ (Figure S3) to eliminate the non-reversible electrochemical processes. In fact, we observed similar transistor behaviors, both in terms of $I-V$ characteristic and on/off current ratio, to those observed by operating within -0.8 to $+0.8 \mathrm{~V}$ in the $\mathrm{pH}$ range 6 to 14 , whereas no transistor performance was observed in the acidic media ( $\mathrm{pH} 0$ to 4 ).

We have also characterized the polymer nanowire-based transistors using an $\mathrm{Ag} / \mathrm{AgCl}$ electrode as a gate electrode instead of Pt wire at different $\mathrm{pH}$ values $(5,7,9,11$ and 13) of the $\mathrm{NaCl}$ electrolyte solutions. All the devices show similar $I_{\mathrm{sd}}-V_{\mathrm{sd}}$ characteristic curves with that observed using Pt wire as gate electrode. The $I_{\mathrm{sd}}-V_{\mathrm{g}}$ plots are shown in Figures S4 and S5 for 
both polyaniline and polypyrrole nanowire-based transistors. We found only a slight change in the threshold gate voltages. 

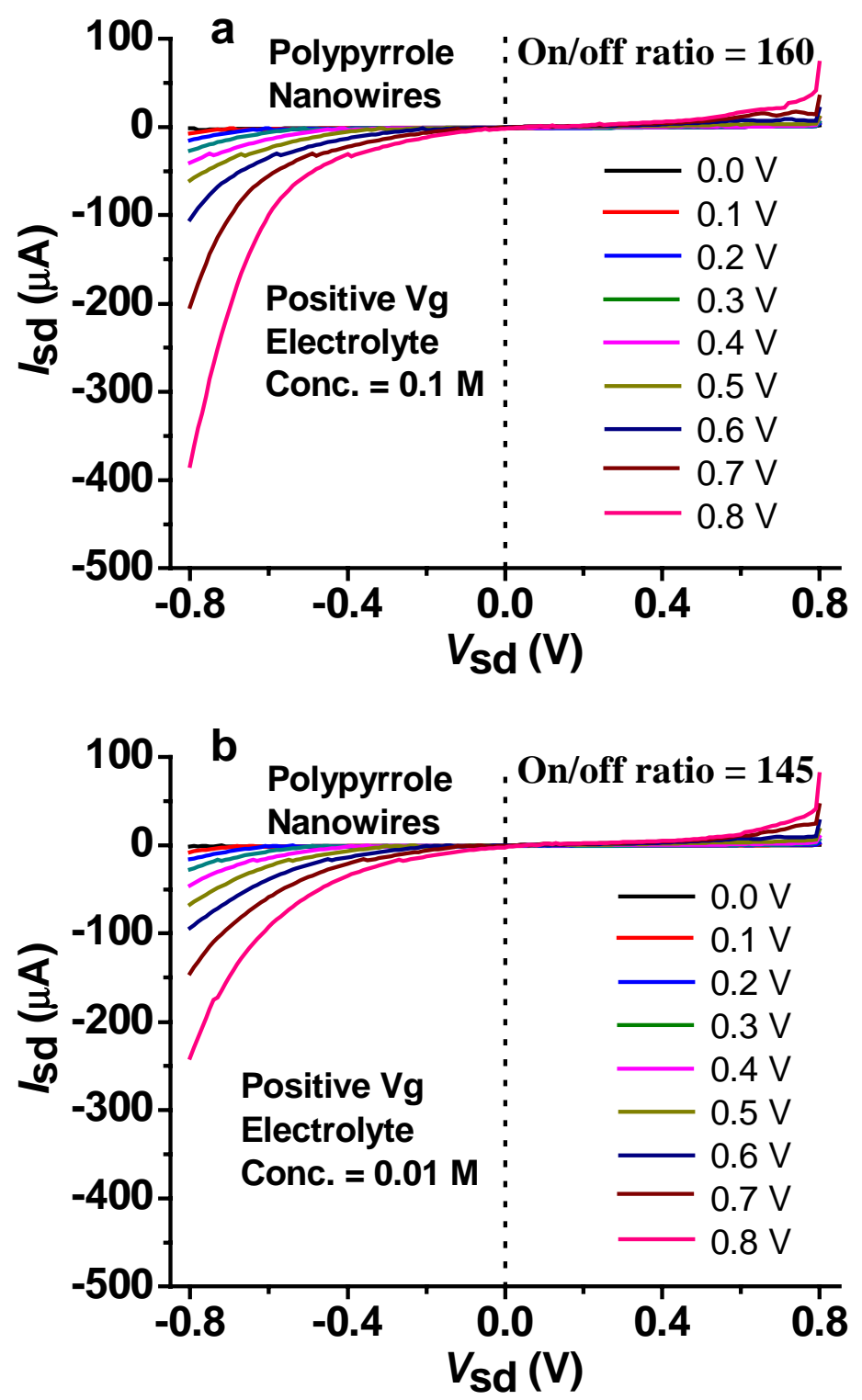

Figure S1. The $I_{\mathrm{sd}}-V_{\mathrm{sd}}$ characteristics of polypyrrole nanowire-based transistors under positive gate biases $\left(V_{\mathrm{g}}=0\right.$ to $0.8 \mathrm{~V}$; step $=0.1 \mathrm{~V}$; gate voltage sweep rate $=0.1 \mathrm{~V} / \mathrm{s}$ ) in (a) $0.1 \mathrm{M}$ and (b) $0.01 \mathrm{M} \mathrm{NaCl}$ electrolyte solutions at $\mathrm{pH} 7 \pm 0.1$. 

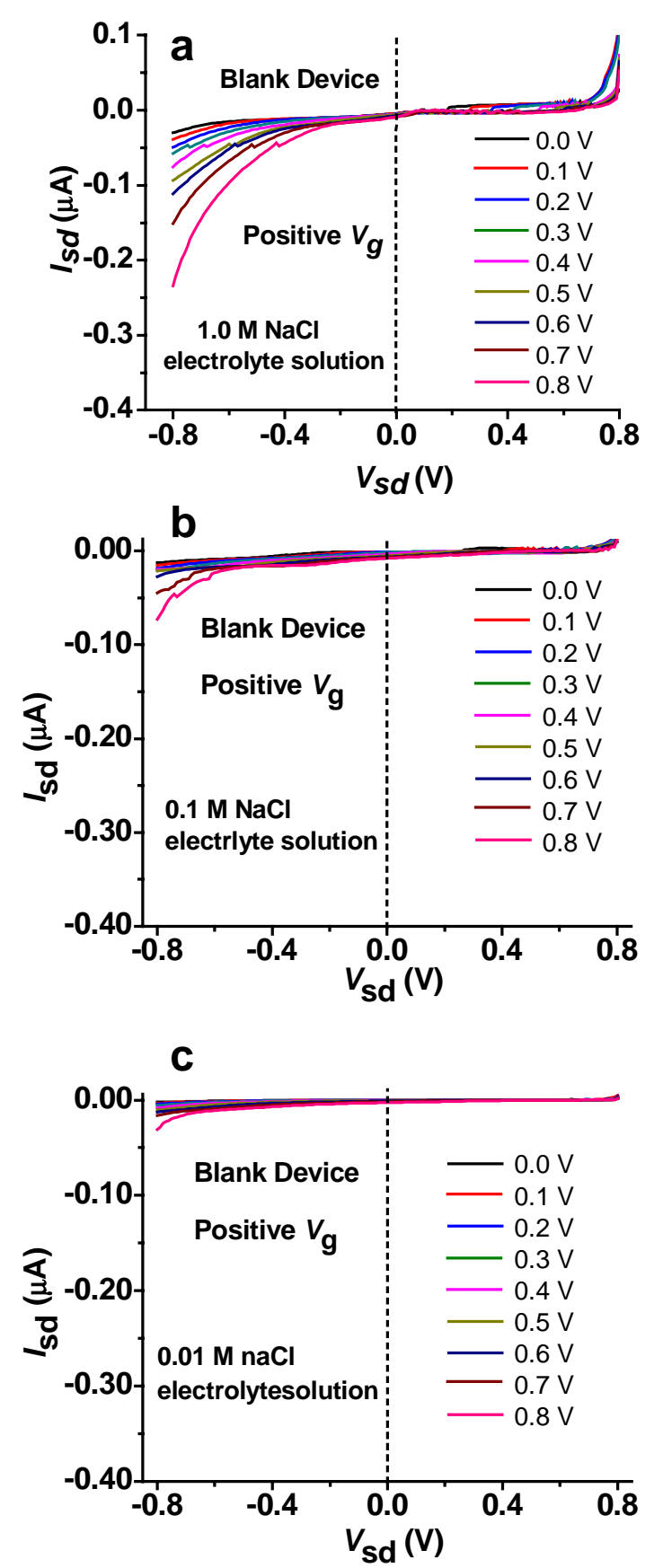

Figure S2. The drain current $\left(I_{\mathrm{sd}}\right)$ versus drain voltage $\left(V_{\mathrm{sd}}\right)$ characteristics of blank devices in (a) $1.0 \mathrm{M}$, (b) $0.1 \mathrm{M}$ and (c) $0.01 \mathrm{M} \mathrm{NaCl}$ electrolyte solutions under positive gate biases $\left(V_{\mathrm{g}}=0\right.$ to $0.8 \mathrm{~V}$; step $=0.1 \mathrm{~V}$; gate voltage sweep rate $=0.1 \mathrm{~V} / \mathrm{s}$ ) at $\mathrm{pH} 7 \pm 0.1$. 

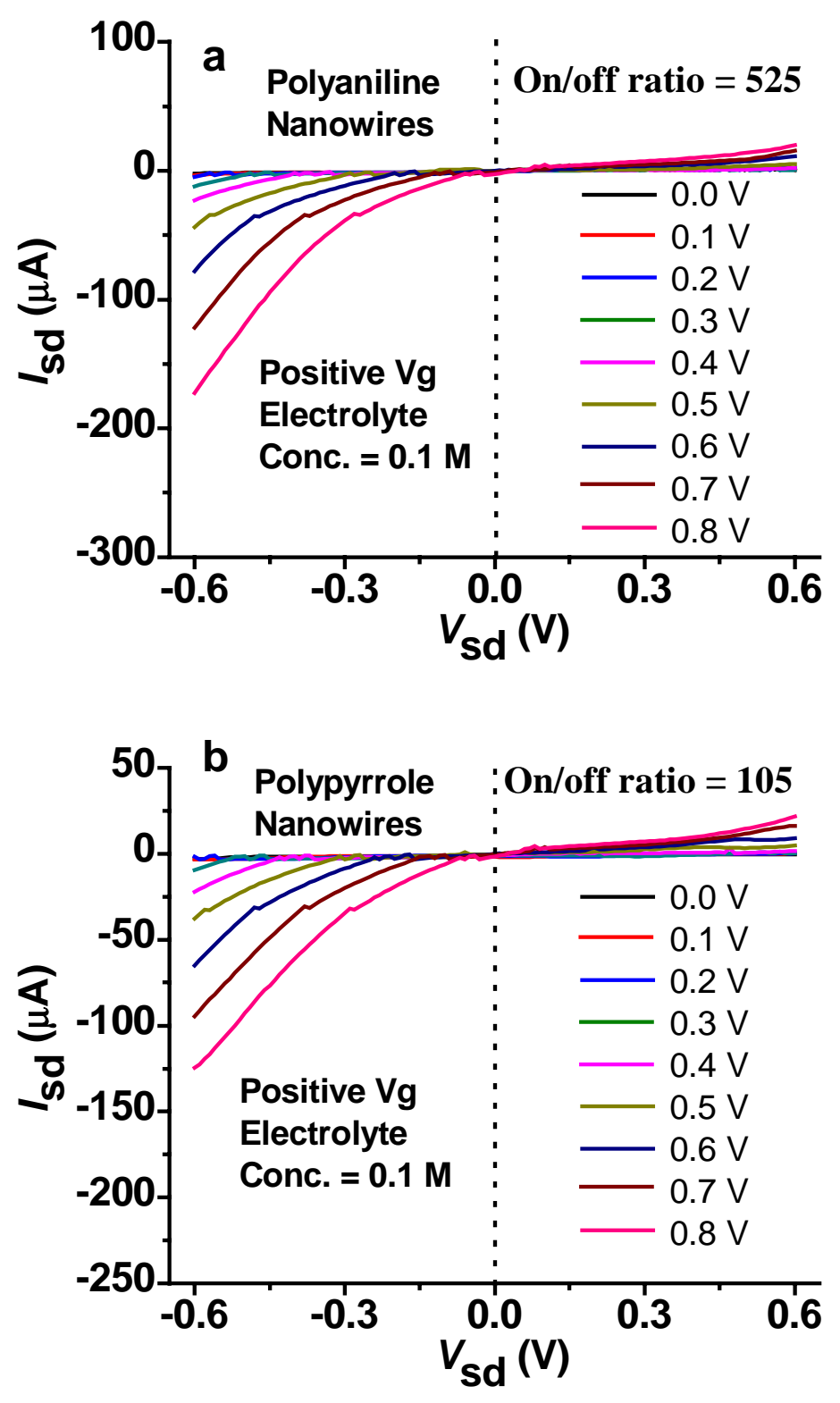

Figure S3. The $I_{\mathrm{sd}}-V_{\mathrm{sd}}$ characteristics of a (a) polyaniline nanowire-based transistors and (b) polypyrrole nanowire-based transistors with a drain-source voltage sweep range -0.6 to $+0.6 \mathrm{~V}$ (sweep rate $=0.01 \mathrm{~V} / \mathrm{s})$ under positive gate biases $\left(V_{\mathrm{g}}=0\right.$ to $0.8 \mathrm{~V}$; step $=0.1 \mathrm{~V}$; gate voltage sweep rate $=0.1 \mathrm{~V} / \mathrm{s}$ ) in $0.1 \mathrm{M} \mathrm{NaCl}$ electrolyte solutions at $\mathrm{pH} 7 \pm 0.1$. 

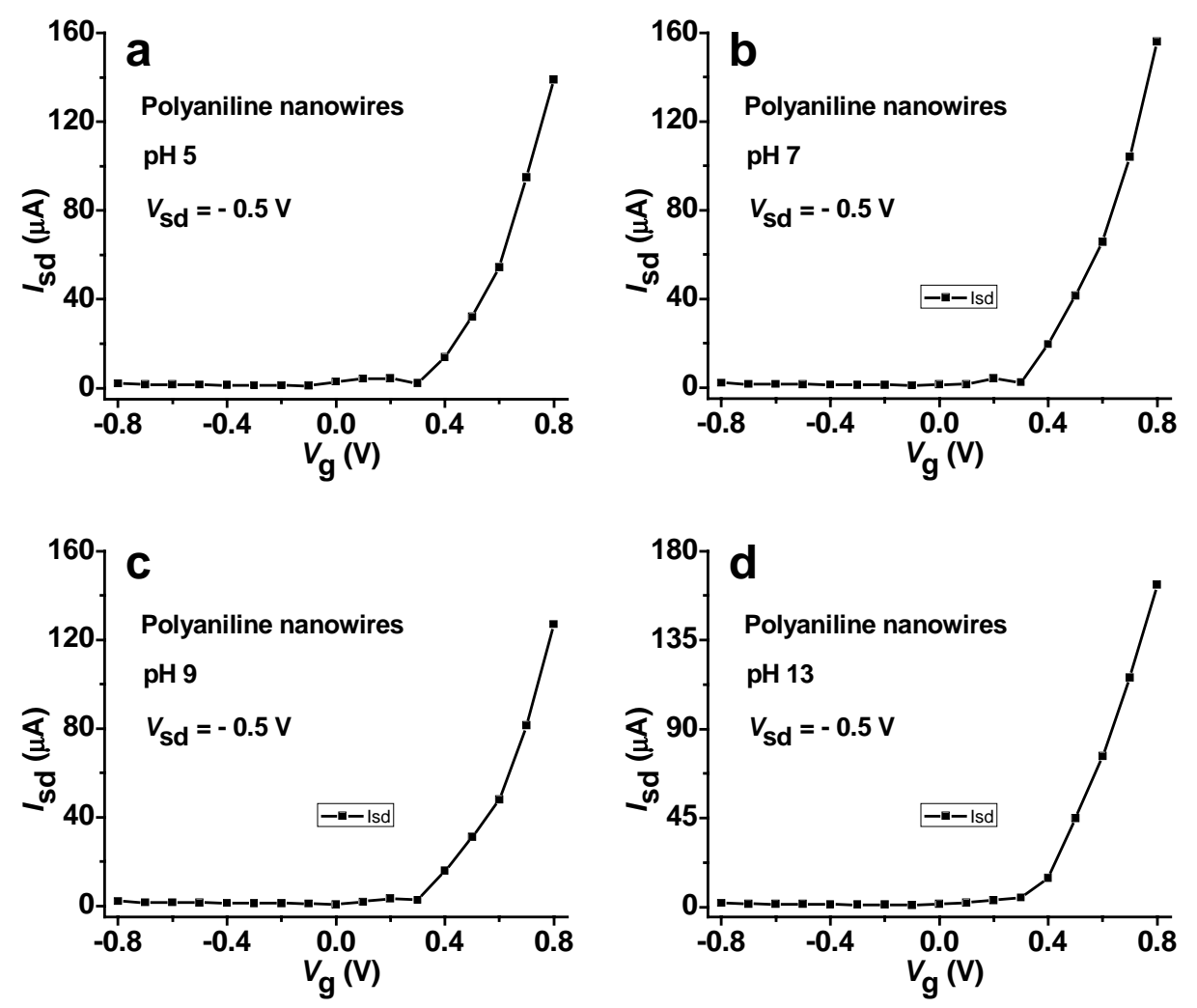

Figure S4. Plots of $\left|I_{\mathrm{sd}}\right|$ versus gate voltage $\left(V_{\mathrm{g}}\right)$ for the polyaniline nanowire-based transistors at a constant $V_{\text {sd }}(-0.5 \mathrm{~V})$ using $\mathrm{Ag} / \mathrm{AgCl}$ as a gate electrode in $1.0 \mathrm{M} \mathrm{NaCl}$ electrolyte solutions at $\mathrm{pH}$ (a) $5 \pm 0.1$, (b) $7 \pm 0.1$, (c) $9 \pm 0.1$, and (d) $13 \pm 0.1$. 

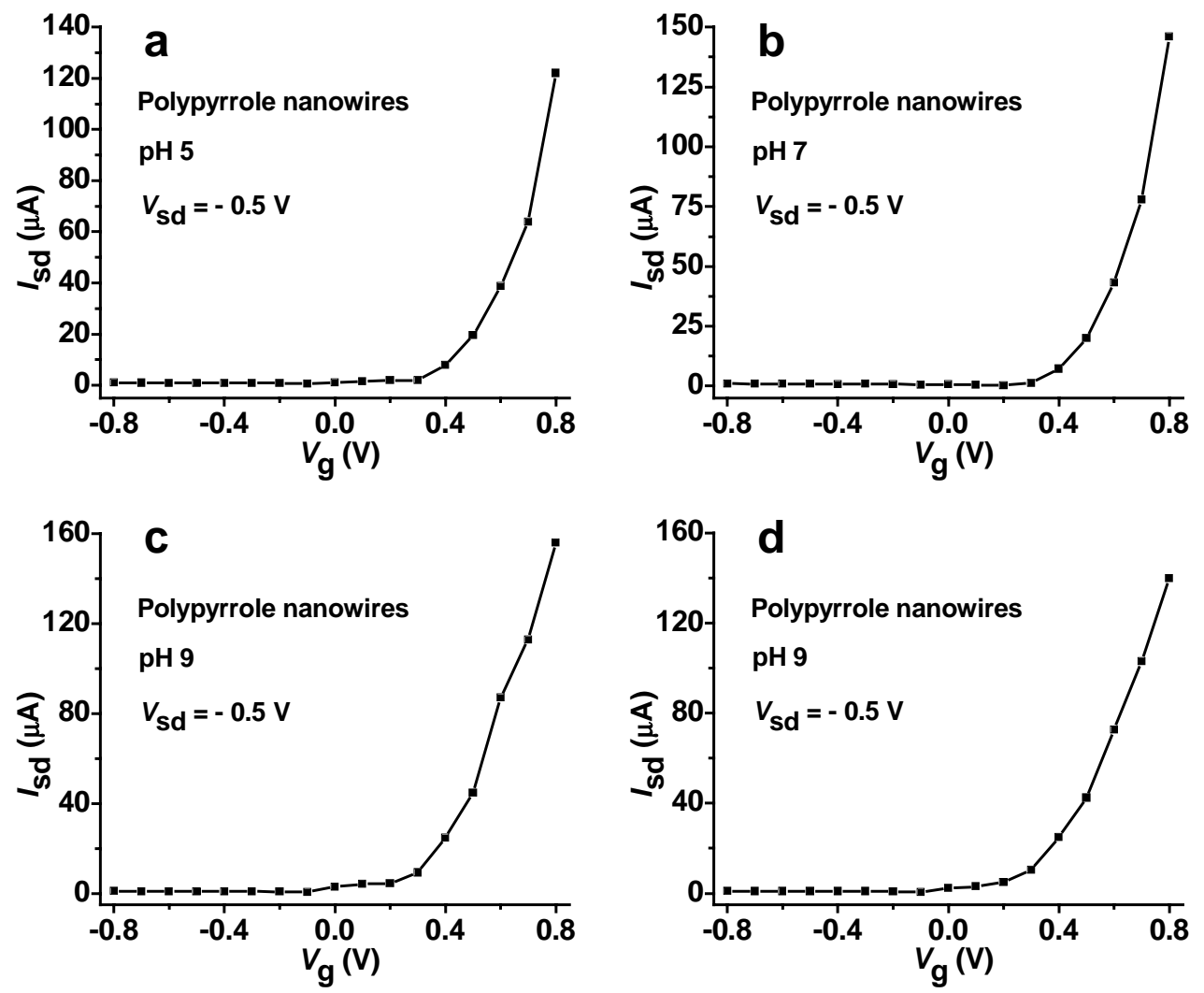

Figure S5. Plots of $\left|I_{\mathrm{sd}}\right|$ versus gate voltage $\left(V_{\mathrm{g}}\right)$ for the polypyrrole nanowire-based transistors at a constant $V_{\text {sd }}(-0.5 \mathrm{~V})$ using $\mathrm{Ag} / \mathrm{AgCl}$ as a gate electrode in $1.0 \mathrm{M} \mathrm{NaCl}$ electrolyte solutions at $\mathrm{pH}$ (a) $5 \pm 0.1$, (b) $7 \pm 0.1$, (c) $9 \pm 0.1$, and (d) $13 \pm 0.1$. 